\title{
Using Kinetic Energy with Potential Energy When Determining Power During the Stair Climbing Test
}

James R. Roush

A.T. Still University, jroush@atsu.edu

John D. Heick

Northern Arizona University, john.heick@nau.edu

Joseph Genovese

A.T. Still University, jgenovese@atsu.edu

Kyle Kurashima

A.T. Still University, Kkurashima@atsu.edu

Dallin Yarrington

A.T. Still University, dyarrington@atsu.edu

Follow this and additional works at: https://nsuworks.nova.edu/ijahsp

Part of the Rehabilitation and Therapy Commons

\section{Recommended Citation}

Roush JR, Heick JD, Genovese J, Kurashima K, Yarrington D. Using Kinetic Energy with Potential Energy When Determining Power During the Stair Climbing Test. The Internet Journal of Allied Health Sciences and Practice. 2020 Jan 01;18(4), Article 5.

This Manuscript is brought to you for free and open access by the College of Health Care Sciences at NSUWorks. It has been accepted for inclusion in Internet Journal of Allied Health Sciences and Practice by an authorized editor of NSUWorks. For more information, please contact nsuworks@nova.edu. 


\title{
Using Kinetic Energy with Potential Energy When Determining Power During the Stair Climbing Test
}

\begin{abstract}
ABSTRACT

Stair climbing is an important functional task that indicates independence, and generating power to climb stairs is a vital component of this task. Power during stair climbing is traditionally calculated using potential energy (PE), but it may be important to determine power expended using kinetic energy (KE).

Purpose: The current study assessed power output for stair climbing with and without the inclusion of KE.

Methods: Sixty participants (21-35 years) climbed a 12-step stairway with a 2-meter acceleration phase before the first step and a 2-meter deceleration phase after the last step. Participants completed 3 trials, and average time was used for calculating energy expended and power.

Results: The mean difference between power from PE and total power was $6.16 \mathrm{~W}\left(\mathrm{SD}=2.50, t_{29}=13.49\right.$, $p<0.001)$ for males and 64.76 W $\left(S D=2.90, t_{29}=8.99, p<0.001\right)$ for females. Agreement between power calculated from PE and total power was 0.99 (95\% confidence interval $=0.98-1.0)$.

Conclusion: Power calculated using PE and KE was significantly different from using PE alone, which may be clinically important. When conducting stair-climbing tests, both PE and KE may be necessary for the most accurate assessment of power.
\end{abstract}

\section{Author Bio(s)}

James R. Roush, PT, PhD, AT, ATC, is a professor emeritus for the physical therapy program at A. T. Still University in Mesa, Arizona.

John D. Heick, PT, DPT, PhD, OCS, NCS, SCS, is an Associate Professor in the Department of Physical Therapy and Athletic Training in Flagstaff, Arizona.

Joseph Genovese, PT, DPT, is a new professional from the physical therapy program at A. T. Still University in Mesa, Arizona.

Kyle Kurashima, PT, DPT, is a new professional from the physical therapy program at A. T. Still University in Mesa, Arizona.

Dallin Yarrington, PT, DPT, is a new professional from the physical therapy program at A. T. Still University in Mesa, Arizona.

Travis LeBaron, PT, DPT, is a new professional from the physical therapy program at A. T. Still University in Mesa, Arizona.

\section{Acknowledgements}

The authors would like to thank Deborah Goggins, MA for her expertise in editing the manuscript. 


\title{
1iJAHSP \\ The Internet Joumnal of Allied Health Sciences and Practice \\ Dedicated to allied health professional practice and education \\ Vol. 18 No. 4 ISSN 1540-580X
}

\section{Using Kinetic Energy with Potential Energy When Determining Power During the Stair Climbing Test}

\author{
James R. Roush ${ }^{1}$ \\ John D. Heick ${ }^{2}$ \\ Joseph Genovese ${ }^{1}$ \\ Kyle Kurashima ${ }^{1}$ \\ Dallin Yarrington ${ }^{1}$ \\ Travis LeBaron ${ }^{1}$
}

1. A.T. Still University

2. Northern Arizona University

United States

\begin{abstract}
Background: Stair climbing is an important functional task that indicates independence and generating power to climb stairs is a vital component of this task. Power during stair climbing is traditionally calculated using potential energy (PE), but it may be important to determine power expended using kinetic energy (KE). Purpose: The current study assessed power output for stair climbing with and without the inclusion of KE. Methods: Sixty participants (21-35 years) climbed a 12-step stairway with a 2-meter acceleration phase before the first step and a 2-meter deceleration phase after the last step. Participants completed 3 trials, and average time was used for calculating energy expended and power. Results: The mean difference between power from PE and total power was $6.16 \mathrm{~W}\left(\mathrm{SD}=2.50, t_{29}=13.49, p<0.001\right)$ for males and $64.76 \mathrm{~W}\left(\mathrm{SD}=2.90, t_{29}=8.99, p<0.001\right)$ for females. Agreement between power calculated from PE and total power was 0.99 (95\% confidence interval $=0.98-1.0)$. Conclusion: Power calculated using PE and KE was significantly different from using PE alone, which may be clinically important. When conducting stair-climbing tests, both PE and KE may be necessary for the most accurate assessment of power.
\end{abstract}

Key Words: Margaria-Kalamen Test, total energy, power output 


\section{INTRODUCTION}

Stair climbing has become an important outcome for many patient populations, such as postsurgical patients, respiratory conditions, or hip and knee arthritis, obese patients, and nursing home residents. ${ }^{1-6,8,10}$ Stair climbing is an excellent functional assessment because it simulates an activity performed in everyday life. The convenience, low cost, and ease of administering the test make stair climbing the ideal functional outcome measure. In clinical practice, it can be used to identify impairments, assess change over time, and measure muscular power. Stair climbing is often assessed in hospitalized patients to determine whether they are able to return home and ascend stairs in their home setting.

The Margaria-Kalamen test, a stair-climbing test commonly used to measure muscular power, uses potential energy $(\mathrm{PE})$ as the key measure to determine power. ${ }^{9-11}$ The PE is calculated as follows: $P E=m g h$, where $m$ is the person's mass $(\mathrm{kg}), \mathrm{g}$ is the gravitational constant $\left(9.8 \mathrm{~m} / \mathrm{s}^{2}\right)$, and $\mathrm{h}$ is the vertical distance of the stairs $(\mathrm{m})$. Power $(\mathrm{W})$ is then calculated as energy divided by time. ${ }^{9}$ Kinetic energy (KE), however, is not normally included in the calculation of total energy and total power for the MargariaKalamen test. ${ }^{9}$ The $\mathrm{KE}$ is calculated as follows: $\mathrm{KE}=1 / 2 m v^{2}$, where $\mathrm{m}$ is the person's mass $(\mathrm{kg})$ and $v$ is the horizontal velocity. To ensure reliability of this functional test, it may be more mathematically accurate to include both PE and KE when calculating power as follows: Total power $=\left(m g h+1 / 2 m v^{2}\right) / t$.

Because Margaria, Aghemo, and Rovelli did not provide a rationale for including only PE in the calculation of total energy and power, some have questioned the validity of this test. ${ }^{9}$ Perhaps the authors were more concerned with the anaerobic energy supply and anaerobic power. However, differences in these calculations (PE only vs both PE and KE) may result in different outcomes, which would affect clinical decision-making and justification of the plan of care in relation to physical function. Therefore, the purpose of the current study was to assess power output for stair climbing with and without the inclusion of KE in the calculation. Such information may be useful for determining the most accurate method to calculate total energy and power for the stair-climbing test.

\section{MATERIALS AND METHODS \\ Study Design}

The current study used a quasi-experimental, repeated measures design. Outcome measures included time ascending the stairs, $\mathrm{PE}, \mathrm{KE}$, and power with and without KE. Independent variables included the calculation of power with and without $\mathrm{KE}$ and the dependent variable was power.

\section{Procedures}

The local institutional review board approved the study. All participants were informed of the benefits and risks of the study before signing an institutionally approved informed consent form to participate. Potential participants were graduate students from a local university who were recruited via flyers and word-of-mouth.

Participants were included in the study if they were aged between 21 and 35 years, had adequate English proficiency to follow simple instructions, and were able to ambulate independently a minimum of $150 \mathrm{ft}(45.72 \mathrm{~m})$ without the use of an assistive device. Using the lowa Level of Assistance Scale, independence was defined as being able to perform the activity safely without the supervision of another individual in the room. ${ }^{17}$ Exclusion criteria were lower extremity surgery within the past year, lower extremity amputation within the past year, or diagnosis with a neurologic condition, such as Parkinson disease or stroke with lower extremity involvement.

After meeting eligibility requirements and providing consent, the following demographic characteristics of participants were obtained: sex, age, height, weight, and body mass index (BMI). Height was measured using a standard stadiometer and recorded in centimeters; weight was measured using a standard bathroom scale and recorded in kilograms. The BMI was calculated using the participant's height and weight.

\section{Instrumentation}

A 12-step staircase was used in the current study. Each step was $16.5 \mathrm{~cm}$ (6.5 in). Total vertical height of the staircase was 191 $\mathrm{cm}$ (75.2 in), and total horizontal distance of the staircase was $301 \mathrm{~cm}$ (118.5 in). There was a 2-meter acceleration phase before the first step, and a 2-meter deceleration phase: both were marked on the floor with masking tape.

Two Lafayette Instrument Company Model 63501IR infrared sensors (Lafayette, IN) were connected to a Lafayette Instrument Company Model 54060 timing device and were used to record each participant's time. One sensor was placed on the platform below the first step and one sensor was on the last step. As the participant ascended the first step, the timing device was triggered 
to start timing; and after the last step, the timing device was again triggered to stop timing. The timing device had reported accuracy to 0.001 seconds.

Participants were instructed on stair climbing using the stair climbing protocol. They began the test $2 \mathrm{~m}$ in front of the stairs, ascended the stairs, and continued walking until they reached the back wall approximately $2 \mathrm{~m}$ past the last step. The participants were instructed to ascend each step independently and to not "skip" any steps. They were also instructed to resist using the handrails on the stairs unless necessary for balance and safety. Since no other verbal cues were given, the participants were instructed to start ascending the staircase when ready. Each participant completed 3 trials of stair climbing. Because of the nature of the task, participants could rest after a trial if needed, or they could perform another trial. The average time ascending the stairs was calculated from the 3 trials and was used for calculation of energy expended. The PE expended when ascending the stairs was calculated as follows: $\mathrm{PE}=m g h$, where $\mathrm{m}$ was the mass $(\mathrm{kg})$ of the participant, $\mathrm{g}$ was the gravitational constant $\left(9.8 \mathrm{~m} / \mathrm{s}^{2}\right)$, and $h$ was the vertical distance $(m)$ of the staircase. The KE when ascending the stairs was calculated as follows: $K E=1 / 2 m v^{2}$, where $\mathrm{m}$ was the participant's mass $(\mathrm{kg})$ and $\mathrm{v}$ was the horizontal velocity $(\mathrm{m} / \mathrm{s})$. Power was calculated as the energy divided by time.

\section{Statistical Analyses}

All data were analyzed separately based on participant sex. Mean and standard deviation (SD) was calculated for age, height, weight, BMI, average time when ascending the stairs, power calculated from only PE when ascending the stairs, power calculated from only KE when ascending the stairs, and total power (PE and KE) when ascending the stairs. A $t$ test was used to test for differences between the power calculated from only PE and total power. These results were reported using mean, SD, and 95\% confidence interval $(\mathrm{Cl})$ with associated effect size and statistical power. An intraclass correlation coefficient (ICC) was calculated to determine agreement between power calculated from only PE and total power. A Pearson product moment correlation coefficient was calculated to determine the relationship between power calculated from only PE and total power. Bland-Altman plots were used to observe agreement in outcomes for power output with and without KE. Significance level was set a priori at 0.05 . Microsoft Excel (Redmond, WA) and SPSS version 23.0 statistical software (IBM, Chicago, IL) were used for data collection and analysis.

\section{RESULTS}

Sixty participants (30 male, 30 female) completed the study. Descriptive statistics for study participants are summarized in the Table.

\section{Stair Climbing Results for Males}

The mean difference between power using only PE and total power was $6.16 \mathrm{~W}\left(\mathrm{SD}=2.50, t_{29}=13.49, p<0.001 .95 \% \mathrm{Cl}=5.27\right.$ 7.06). The effect size for the $t$ test was 2.46 , and the statistical power was 0.84 . The ICC $(2,1)$ for power calculated from only PE and total power was $0.99(95 \% \mathrm{Cl}=0.98-1.0)$. The percent difference when using $\mathrm{PE}$ alone versus $\mathrm{PE}$ and $\mathrm{KE}$ combined was $1.6 \%$. The relationship of power from only PE as a function of total power is presented in Figure 1. The Pearson product moment correlation coefficient for power calculated from only PE and total power was $0.99(t=37.79, p<0.001,95 \% \mathrm{Cl}=0.98-1.0)$. As shown in the Bland-Altman plot (Figue 2), the bias line was not close to zero, and there was a definite pattern to the data points with one noticable outlier. The lines representing $2 \mathrm{SD}$ above and below the bias line were $20 \mathrm{~W}$, which may be clinically important. Given the plot of agreement for power output with and without KE, there may be a clinically important bias between power calculated from PE when ascending the stairs and total power when ascending the stairs, especially at higher levels of calculated power.

\section{Stair Climbing Results for Females}

The mean difference between power using only PE and total power was $4.76 \mathrm{~W}\left(\mathrm{SD}=2.90, t_{29}=8.99, p<0.001 .95 \% \mathrm{Cl}=0.98\right.$ 1.0). The effect size was 1.64 , signifying a large effect that was clinically important, and the statistical power was 0.99 . The relationship of power from only PE as a function of total power is presented in Figure 3. The Pearson product moment correlation coefficient for power calculated using only PE and total power was $0.999\left(t_{28}=37.79, p<0.001,95 \% \mathrm{Cl}=0.98-1.0\right)$. The power for the $t$ test determining the relationship between power using only PE and total power was 0.82 . The addition of KE to the total power again generated approximately $1.6 \%$ more power to climb the stairs. As shown in the Bland-Altman plot (Figure 4), the bias line was approximately $5 \mathrm{~W}$ from zero. The difference between the 2 dispersal lines representing $2 \mathrm{SD}$ above and below the bias line was $11.60 \mathrm{~W}$, representing a large difference. There was a definite pattern to the data points with a large correlation between points on the plot and 3 distinct outliers 
Table. Demographic characteristics and stair-climbing test outcomes of study participants ( $\mathrm{N}=60)$

\begin{tabular}{lll}
\hline Variable & Mean $(\mathbf{S D})$ & \\
\cline { 2 - 3 } & Male $(\mathbf{n}=\mathbf{3 0})$ & Female $(\mathbf{n}=\mathbf{3 0})$ \\
\hline Age, $\mathrm{y}$ & $26.73(2.75)$ & $26.46(2.32)$ \\
Height, cm & $177.74(7.23)$ & $164.78(6.46)$ \\
Weight, kg & $79.00(21.75)$ & $63.33(7.75)$ \\
Body mass index & $24.98(6.19)$ & $23.32(2.52)$ \\
Average time for stair climbing, s & $3.99(0.48)$ & $4.15(0.63)$ \\
Power from potential energy, W & $380.60(84.81)$ & $293.50(64.44)$ \\
Power from kinetic energy, W & $6.16(2.50)$ & $4.76(2.90)$ \\
Total power, W & $386.76(86.80)$ & $298.25(67.11)$ \\
\hline
\end{tabular}

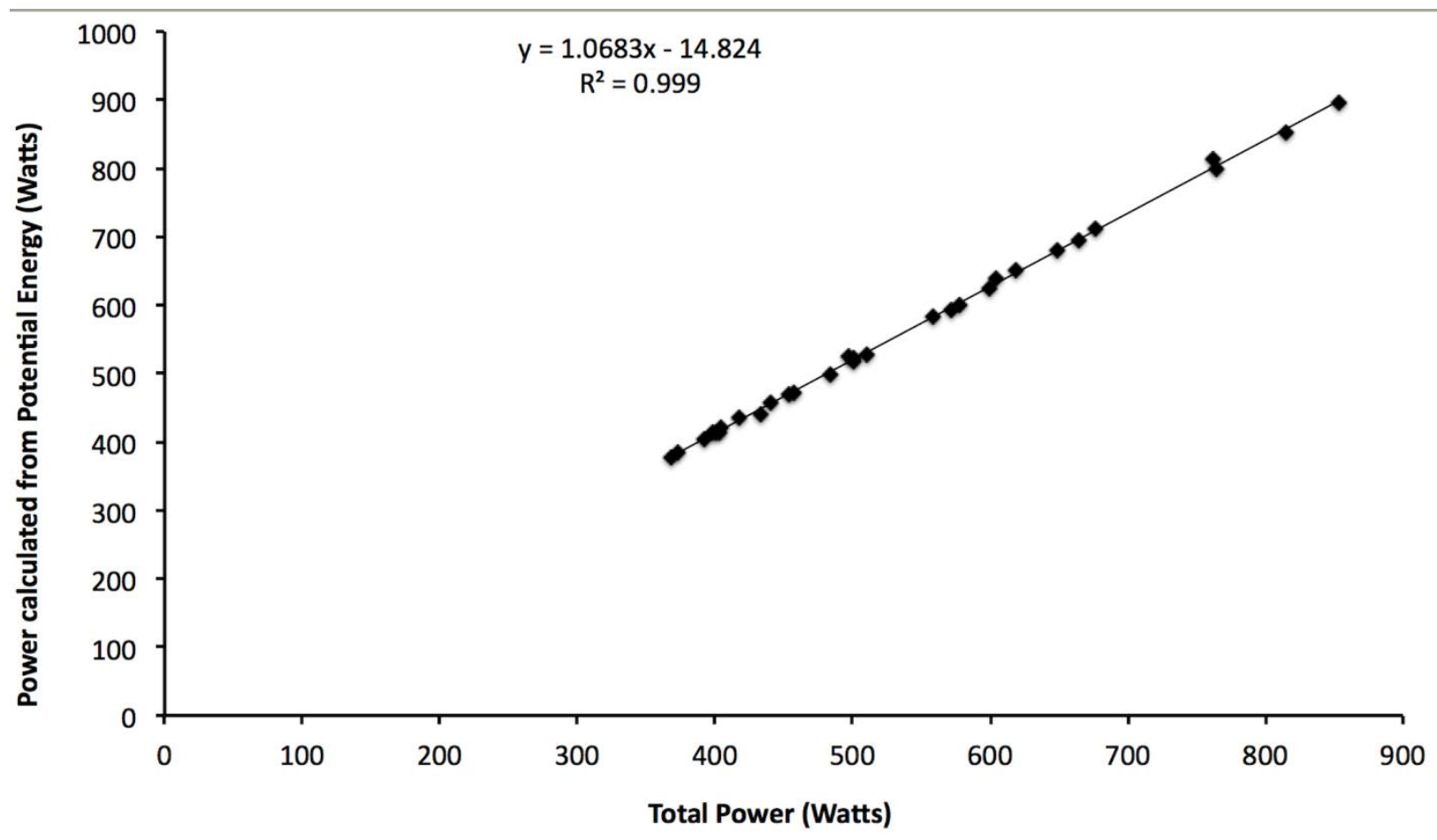

Figure 1. Correlation plot of power calculated from potential energy as a function of total power for male participants ( $n=30)$ 


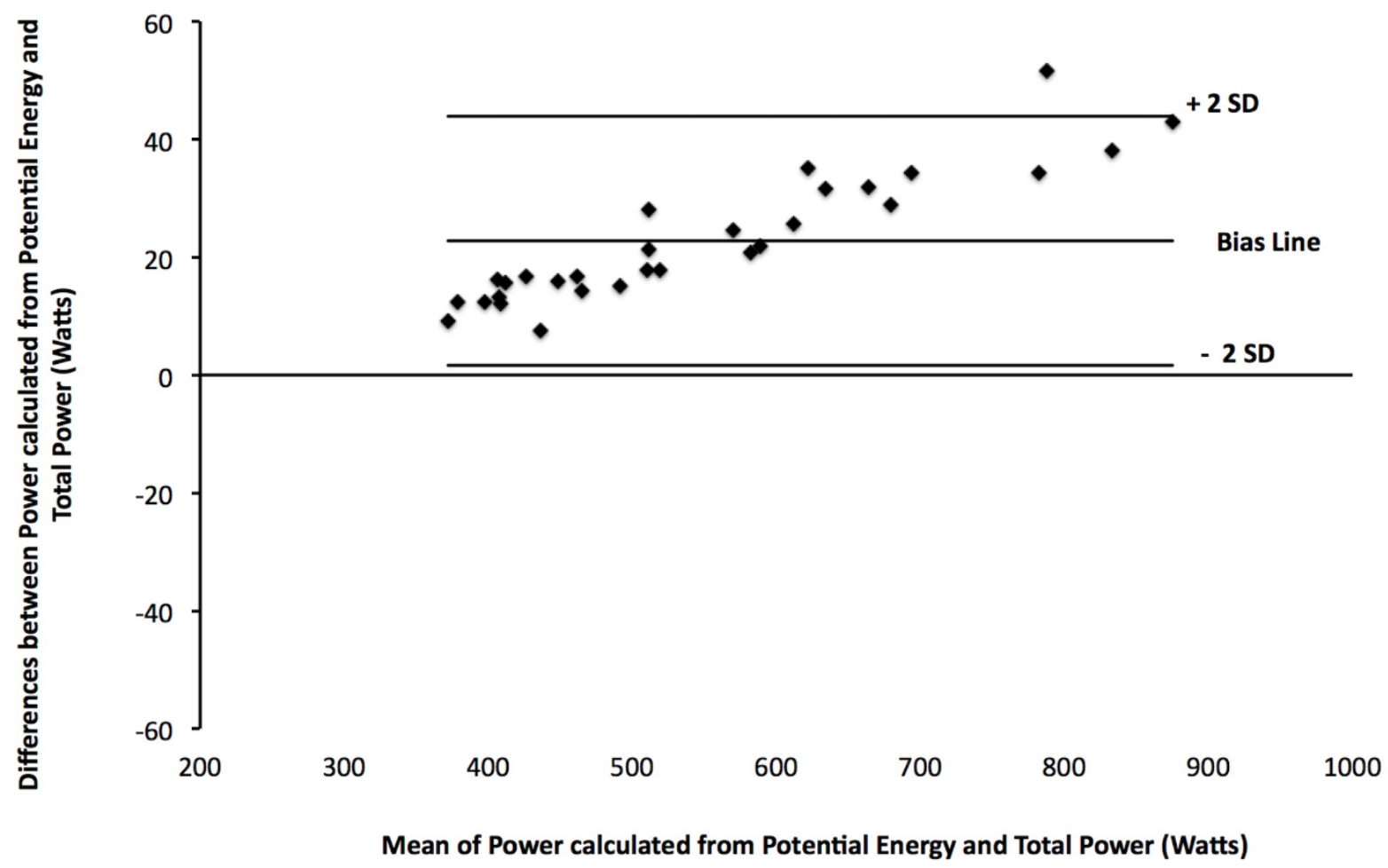

Figure 2. Bland-Altman plot of the differences between power calculated from potential energy and total power as a function of the mean of potential energy and total power for male participants $(n=30)$

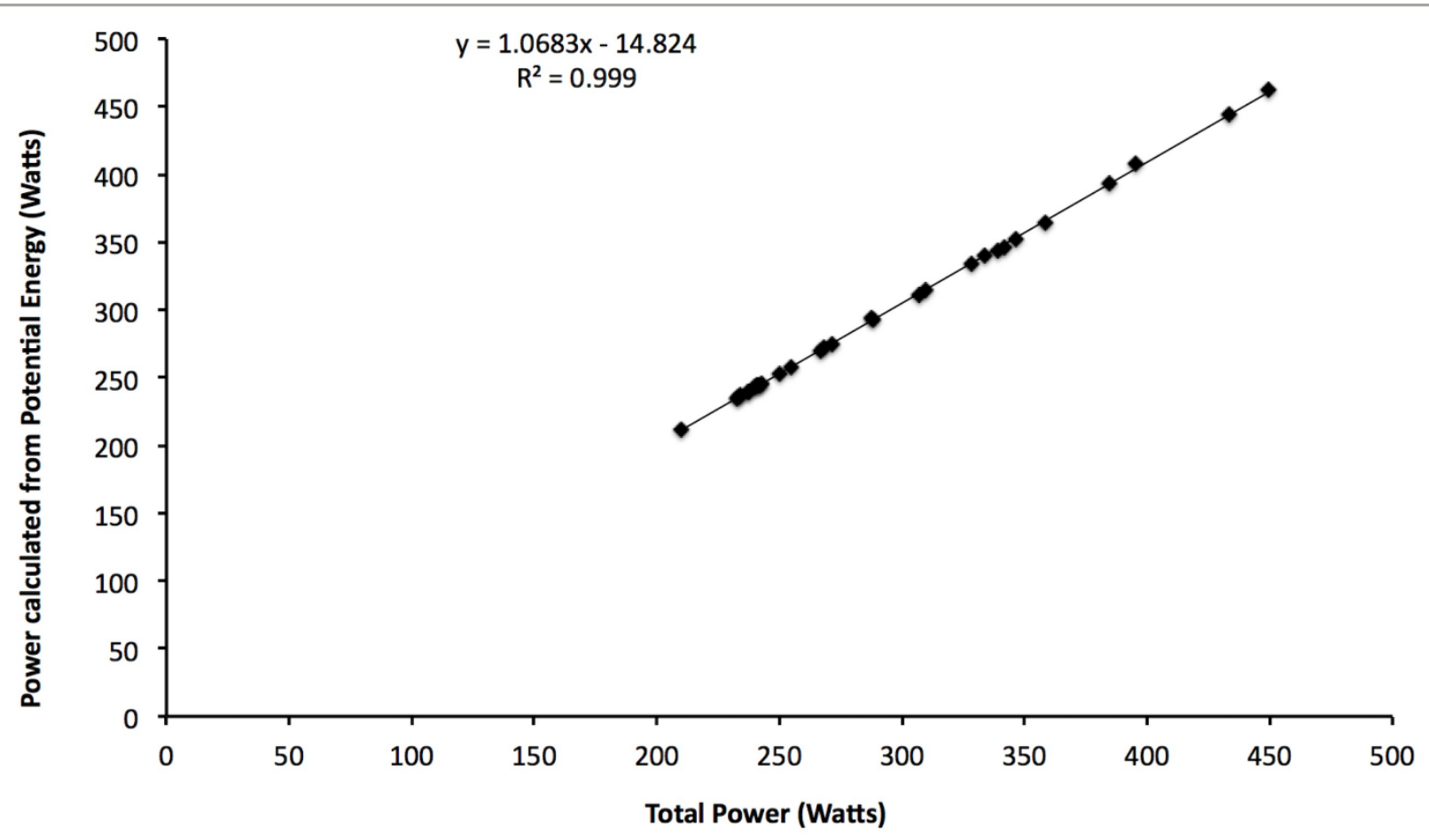

Figure 3. Correlation plot of power calculated from potential energy as a function of total power for female participants ( $n=30$ ) 


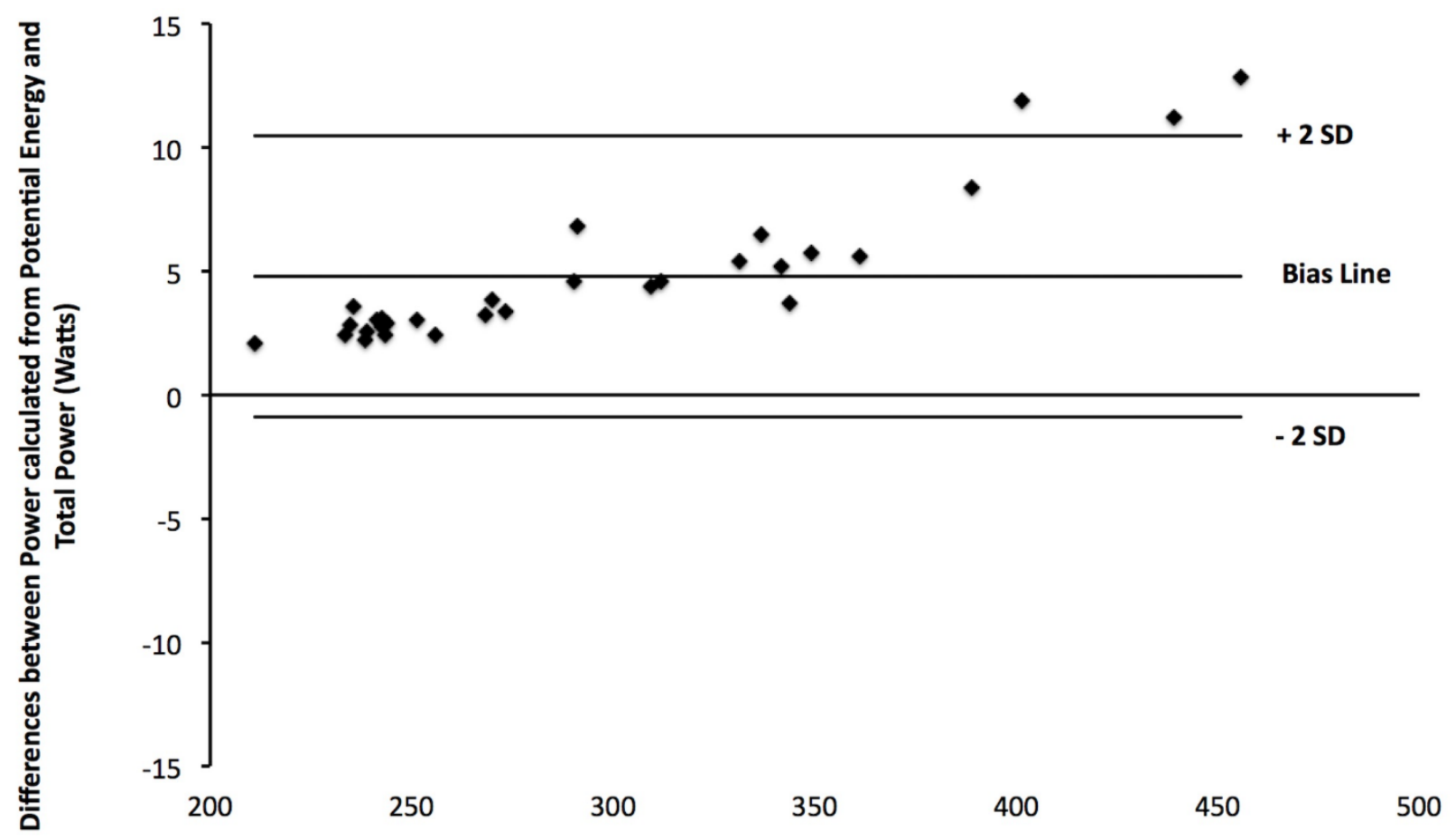

Mean of Power calculated from Potential Energy and Total Power (Watts)

Figure 4. Bland-Altman plot of the differences between power calculated from potential energy and total power as a function of the mean of potential energy and total power for female participants $(n=30)$

\section{DISCUSSION}

Results of the current study suggested that KE should be considered in the calculation of total power for the stair-climbing test, especially given the meaningful effect it had on power outcomes in young adult males. To our knowledge, no other studies have investigated including both PE and KE in the total power calculation of this test even though stair climbing is a widely used outcome measure in clinical practice because of its availability and ease of administration when compared to other functional capacity assessment tools. Although we found a total power mean difference of less than $2 \%$, the large effect size supports the use of KE in the calculation of total power since it improves the accuracy of power measurements.

Stair climbing has been used as a functional outcome measure in many studies. ${ }^{4,11-13,14-38}$ Power has also been calculated in many studies by first determining the PE and then dividing the PE by the duration of time to ascend a set of

stairs. ${ }^{11-13,23,24,28,29,31,37}$ Stair climbing has been used as an item on self-reported outcome measures. ${ }^{17-19,37}$ It has also been used for the assessment of patients with numerous medical issues, such as lung cancer, cardiac disease, hip and knee osteoarthritis, total knee arthroplasty and total hip arthroplasty, obesity, and chronic obstructive pulmonary disease and for assessment of independent, community-dwelling adults. $., 17,18,20,26-28,30-34,36$ Previous authors have endorsed the stair-climbing test for its simplicity, lack of expense, ease of administration, and ability to assess functional performance using an activity of daily living..$^{16,27}$ In particular, the ease of use makes this test ideal for everyday clinical practice.

In a study by Koegelenberg, Diacon, Irani, and Bolliger, the average velocity of stair ascent was strongly correlated with maximal oxygen uptake $\left(\mathrm{VO}_{2}\right.$ max) values in lung resection candidates, which suggested the stair-climbing test could be used as a clinical substitute for $\mathrm{VO}_{2}$ max testing. ${ }^{27}$ Measurement of power in stair climbing has been shown to be clinically relevant because it helps clinicians formulate a plan of care based on performance..$^{38}$ In older adults with mobility deficits, Bean et al demonstrated stair climbing power tests are relevant for screening individuals at risk of disability. ${ }^{14}$ Because this test efficiently identifies individuals at risk for disability, it allows clinicians to establish an appropriate plan of care for these patients. For individuals with chronic obstructive pulmonary disease, Roig et al showed stair climbing tests may provide valuable information related to the plan of care. In this population, understanding functional deficits of patients allows clinicians to focus efforts on interventions specific to the need of the patient. ${ }^{30}$ 
In a review of outcome measures for functional capacity and overall strength and physical activity, Granger et al reported stair climbing was strongly correlated with cardiopulmonary exercise tests (CPET) in individuals with small cell cancer. ${ }^{31}$ Although CPET is the gold standard test for measuring functional capacity, it may not be readily available to clinicians due to the cost of equipment. The study by Granger et al also found the altitude reached during stair climbing and $\mathrm{VO}_{2}$ peak were strongly correlated in individuals with small cell cancer. ${ }^{21}$ Further, the incremental shuttle walk and stair-climbing tests were highly correlated with the CPET, suggesting that both of these tests could be used in multiple clinical settings including a patient's home with stairs. ${ }^{21}$ Overall, these results suggest stair climbing could be used as an assessment of power and as a comparison after rehabilitation for multiple patient populations.

The lack of stair climbing studies investigating differences in the power calculation using PE only versus PE and KE combined should be addressed with additional studies in multiple populations. The current study evaluated this calculation difference in healthy young adults. Our results suggested the simplicity of including PE and KE makes the power calculation a more precise measure. As seen in the Bland-Altman plot, as velocity increased, there was a larger change in the calculated power, making it more important to include kinetic energy for stair climbing at higher velocities. When stair climbing is used as an assessment of power, more precise total power values may influence clinical decisions in multiple patient populations.

It is unknown how these power values would change in other patient populations such as older adults and athletes. The current study used a convenience sample of healthy adults, and future studies should investigate multiple populations using a more precise measure of power. A study by Zeni and Synder-Mackler concluded stair climbing may have a ceiling effect that makes it less effective in some patient populations. ${ }^{36}$ However, this conclusion requires further investigation since most participants or patients are instructed to walk up the stairs one step at a time at their normal walking speed. A ceiling effect may be found in competitive athletes because their normal walking speed would be more rigorous. Therefore, this effect should be investigated to provide normative values for individual sports that require power. Further, athletes recovering from injury, and perhaps specifically lower extremity injury, could use the stair-climbing test as a before and after measure to show them the power gained and needed for their individual sport.

The effect of aging on stair climbing has been investigated in a few studies. In one study, participants were aged between 74 and 98 years, and in another, the mean age of participants was 80 years. ${ }^{37,38}$ One patient population that needs further investigation is frail individuals. Frailty can be defined as unintentional weight loss greater than 10 pounds (4.5 kilograms), self-reported exhaustion, weakness as measured by grip strength, slow walking speed, and low physical activity. ${ }^{38}$ Given results of the current study, a population of frail individuals may benefit the most from the inclusion of power into their exercise program. Certainly, more studies are needed in this population.

\section{Limitations}

There are several limitations that may have impacted results of the current study. Our participants were recruited by convenience sampling, which may result in bias in terms of willingness to participate. In addition, some participants were motivated to ascend the stairs as quickly as possible to obtain the fastest time and beat their previous trial, which may have affected the overall power averages calculated in the study. Future studies should consider not telling participants their time values after each trial to minimize the competitive nature of the participant.

\section{CONCLUSION}

Stair climbing is a commonly used measure in multiple patient populations because of its low cost and ease of administration. As shown in the current study, power when calculated using PE and KE combined is significantly different from using only PE. Therefore, when implementing stair-climbing tests, consideration of both PE and KE is necessary for the most accurate assessment of power during stair climbing.

\section{REFERENCES}

1. Loyd BJ, Jennings JM, Judd DL, et al. Influence of Hip Abductor Strength on Functional Outcomes Before and After Total Knee Arthroplasty: Post Hoc Analysis of a Randomized Controlled Trial. Phys Ther. 2017;97(9):896-903. PMID:28969350

2. Bade MJ, Struessel T, Dayton M, et al. Early High-Intensity Versus Low-Intensity Rehabilitation After Total Knee Arthroplasty: A Randomized Controlled Trial. Arthritis Care Res (Hoboken). 2017;69(9):1360-1368. PMID:27813347

3. Walterspacher S, Walker DJ, Kabitz HJ, Windisch W, Dreher M. The effect of continuous positive airway pressure on stair-climbing performance in severe COPD patients. COPD. 2013;10(2):193-199. PMID:23547631

(c) The Internet Journal of Allied health Sciences and Practice, 2020 
4. Zeni JA, Jr., Axe MJ, Snyder-Mackler L. Clinical predictors of elective total joint replacement in persons with end-stage knee osteoarthritis. BMC Musculoskelet Disord. 2010;11:86.

5. lijima H, Eguchi R, Shimoura K, Aoyama T, Takahashi M. Stair climbing ability in patients with early knee osteoarthritis: Defining the clinical hallmarks of early disease. Gait Posture. 2019;72:148-153. PMID:31202024

6. Sartorio A, Lafortuna CL, Agosti F, Proietti M, Maffiuletti NA. Elderly obese women display the greatest improvement in stair climbing performance after a 3-week body mass reduction program. International journal of obesity and related metabolic disorders : journal of the International Association for the Study of Obesity. 2004;28(9):1097-1104. PMID:15211371

7. Grant S, Todd K, Aitchison TC, Kelly P, Stoddart D. The effects of a 12-week group exercise programme on physiological and psychological variables and function in overweight women. Public Health. 2004;118(1):31-42. PMID:14643625

8. Johnen B, Schott N. Feasibility of a machine vs free weight strength training program and its effects on physical performance in nursing home residents: a pilot study. Aging Clin Exp Res. 2018;30(7):819-828. PMID:28980220

9. Margaria R, Aghemo P, Rovelli E. Measurement of muscular power (anaerobic) in man. Journal of applied physiology. 1966;21(5):1662-1664. PMID:5923240

10. Brooks GA, Fahey TD, White TP. Exercise physiology: Human bioenergetics and its applications. Mayfield publishing company; 1996.

11. Reiman MP, Peintner AM, Boehner AL, Cameron CN, Murphy JR, Carter JW. Effects of dynamic warm-up with and without a weighted vest on lower extremity power performance of high school male athletes. J Strength Cond Res. 2010;24(12):3387-3395. PMID:21088550

12. Cacolice PA, Carcia CR, Scibek JS, Phelps AL. The Use of Functional Tests to Predict Sagittal Plane Knee Kinematics in Ncaa-D1 Female Athletes. Int J Sports Phys Ther. 2015;10(4):493-504. PMID:26346734

13. Shields RK, Leo KC, Miller B, Dostal WF, Barr R. An acute care physical therapy clinical practice database for outcomes research. Physical therapy. 1994;74(5):463-470. PMID:8171108

14. Bean JF, Kiely DK, Herman S, et al. The relationship between leg power and physical performance in mobility-limited older people. J Am Geriatr Soc. 2002;50(3):461-467. PMID:11943041

15. Bean JF, Kiely DK, LaRose S, Alian J, Frontera WR. Is stair climb power a clinically relevant measure of leg power impairments in at-risk older adults? Arch Phys Med Rehabil. 2007;88(5):604-609. PMID:17466729

16. Bennell K, Dobson F, Hinman R. Measures of physical performance assessments: Self-Paced Walk Test (SPWT), Stair Climb Test (SCT), Six-Minute Walk Test (6MWT), Chair Stand Test (CST), Timed Up \& Go (TUG), Sock Test, Lift and Carry Test (LCT), and Car Task. Arthritis Care Res (Hoboken). 2011;63 Suppl 11:S350-370. PMID:22588756

17. Brunelli A, Pompili C, Berardi R, et al. Performance at preoperative stair-climbing test is associated with prognosis after pulmonary resection in stage I non-small cell lung cancer. Ann Thorac Surg. 2012;93(6):1796-1800. PMID:22551844

18. Brunelli $A$, Refai $M$, Xiume $F$, et al. Performance at symptom-limited stair-climbing test is associated with increased cardiopulmonary complications, mortality, and costs after major lung resection. Ann Thorac Surg. 2008;86(1):240-247; discussion 247-248. PMID:18573431

19. Butler AA, Menant JC, Tiedemann AC, Lord SR. Age and gender differences in seven tests of functional mobility. J Neuroeng Rehabil. 2009;6:31. PMID:19642991

20. Galea MP, Levinger P, Lythgo N, et al. A targeted home- and center-based exercise program for people after total hip replacement: a randomized clinical trial. Arch Phys Med Rehabil. 2008;89(8):1442-1447. PMID:18586222

21. Granger CL, McDonald CF, Parry SM, Oliveira CC, Denehy L. Functional capacity, physical activity and muscle strength assessment of individuals with non-small cell lung cancer: a systematic review of instruments and their measurement properties. BMC Cancer. 2013;13:135. PMID:23514337

22. Herman S, Kiely DK, Leveille S, O'Neill E, Cyberey S, Bean JF. Upper and lower limb muscle power relationships in mobility-limited older adults. J Gerontol A Biol Sci Med Sci. 2005;60(4):476-480. PMID:15933387

23. Hetzler RK, Vogelpohl RE, Stickley CD, Kuramoto AN, Delaura MR, Kimura IF. Development of a modified MargariaKalamen anaerobic power test for American football athletes. J Strength Cond Res. 2010;24(4):978-984. PMID:19996779

24. Huskey T, Mayhew JL, Ball TE, Arnold MD. Factors affecting anaerobic power output in the Margaria-Kalamen test. Ergonomics. 1989;32(8):959-965. PMID:2806226

25. Kalapotharakos VI, Michalopoulos M, Tokmakidis SP, Godolias G, Gourgoulis V. Effects of a heavy and a moderate resistance training on functional performance in older adults. J Strength Cond Res. 2005;19(3):652-657. PMID:16095421

26. Kennedy DM, Stratford PW, Wessel J, Gollish JD, Penney D. Assessing stability and change of four performance measures: a longitudinal study evaluating outcome following total hip and knee arthroplasty. BMC Musculoskelet Disord. 2005;6:3. PMID:15679884 
27. Koegelenberg CF, Diacon AH, Irani S, Bolliger CT. Stair climbing in the functional assessment of lung resection candidates. Respiration. 2008;75(4):374-379. PMID:18272936

28. Lafortuna CL, Fumagalli E, Vangeli V, Sartorio A. Lower limb alactic anaerobic power output assessed with different techniques in morbid obesity. J Endocrinol Invest. 2002;25(2):134-141. PMID:11929084

29. Nedeljkovic A, Mirkov DM, Pazin N, Jaric S. Evaluation of Margaria staircase test: the effect of body size. Eur J Appl Physiol. 2007;100(1):115-120. PMID:17273883

30. Roig M, Eng JJ, Maclntyre DL, Road JD, Reid WD. Associations of the Stair Climb Power Test with muscle strength and functional performance in people with chronic obstructive pulmonary disease: a cross-sectional study. Phys Ther. 2010;90(12):1774-1782. PMID:21030661

31. Sartorio A, Agosti F, De Col A, Lafortuna CL. Age- and gender-related variations of leg power output and body composition in severely obese children and adolescents. J Endocrinol Invest. 2006;29(1):48-54. PMID:16553033

32. Sartorio A, Proietti M, Marinone PG, Agosti F, Adorni F, Lafortuna CL. Influence of gender, age and BMI on lower limb muscular power output in a large population of obese men and women. Int J Obes Relat Metab Disord. 2004;28(1):9198. PMID:14710170

33. Tiedemann A, Shimada H, Sherrington C, Murray S, Lord S. The comparative ability of eight functional mobility tests for predicting falls in community-dwelling older people. Age Ageing. 2008;37(4):430-435. PMID:18487264

34. Valtonen A, Poyhonen T, Heinonen A, Sipila S. Muscle deficits persist after unilateral knee replacement and have implications for rehabilitation. Phys Ther. 2009;89(10):1072-1079. PMID:19713269

35. Verghese J, Wang C, Xue X, Holtzer R. Self-reported difficulty in climbing up or down stairs in nondisabled elderly. Arch Phys Med Rehabil. 2008;89(1):100-104. PMID:18164338

36. Zeni JA, Jr., Snyder-Mackler L. Early postoperative measures predict 1- and 2-year outcomes after unilateral total knee arthroplasty: importance of contralateral limb strength. Phys Ther. 2010;90(1):43-54.

37. Irrgang JJ, Snyder-Mackler L, Wainner RS, Fu FH, Harner CD. Development of a patient-reported measure of function of the knee. J Bone Joint Surg Am. 1998;80(8):1132-1145. PMID:9730122

38. Fried LP, Tangen CM, Walston J, et al. Frailty in older adults: evidence for a phenotype. J Gerontol A Biol Sci Med Sci. 2001;56(3):M146-156. PMID:11253156 